\title{
The property of manufacturability of the architectural system as a component of a single and holistic composite solution
}

\author{
Alexander Pleshivtsev ${ }^{1 *}$ \\ ${ }^{1}$ State University of land management, 105064, 15, Kazakova str., Moscow, \\ Russia
}

\begin{abstract}
Purpose: Analysis of modern methods (theory) of composition as a priority motivation of artistic and creative thinking in the process of architectural activity. Study of the influence of the complex properties of manufacturability on the nature of the formation of composite solutions of architectural systems. Methods and materials: dialectical approach, generally accepted logical research methods (analysis, system approach, generalization) and their synthesis using relevant information materials.Results: the basic means, regularities and principles of composition that determine the features of the formation of architectural systems are established. The analysis of the action of the basic (canonical) law of architectural composition and the conditions for the formation of a holistic and unified compositional solutions. The conceptual apparatus of the category (complex property) of "manufacturability" as a subject feature of the features of manufacturing, transportation, construction and operation of the architectural system is given. The direct nature of the interaction of "canonical" types (functional, constructive, artistic and aesthetic) and technological components in the tectonic display of the properties of the architectural system is established.Conclusions: Manufacturability of architectural systems formation is an equivalent component (in relation to the constructive, functional and artistic-aesthetic components) of a single and integral compositional solution. Indicators of the complex properties of manufacturability largely determine the functional quality of architectural systems.
\end{abstract}

\section{Introduction}

\subsection{Canonical" representation of the composition of architectural systems}

The architectural composition is positioned as the main method of solving problems associated with the formation of the object (in the form of a single and harmonious architectural form that displays a natural, aesthetic and harmonious combination of certain

\footnotetext{
*Corresponding author: perspektiva-aa@mail.ru
} 
types of volumes and spaces), due to the presence of inherent and dominant conditions (eg, function, climate, design, urban situation) of the architectural environment $[1 ; 2 ; 3 ; 4]$.

Architectural composition is characterized by the action of the basic law, which includes a set of specific categories (main and secondary, for example: spatial structure, harmony, proportion, scale), which characterize the main features and characteristics associated with the formation and functioning of the architectural object (figure 1).

The basic law (the law of harmonic unity of content and form) characterizes the most essential and General connections and regularities in the composition. Each of the categories of composition summarizes only essential features. The result of the influence of each of the categories of architectural composition can only be considered separately, since the various properties of the form, manifested in various combinations, interact with each other as part of the integral structure of the object-the architectural system $[5 ; 6 ; 7 ; 8 ; 9]$.

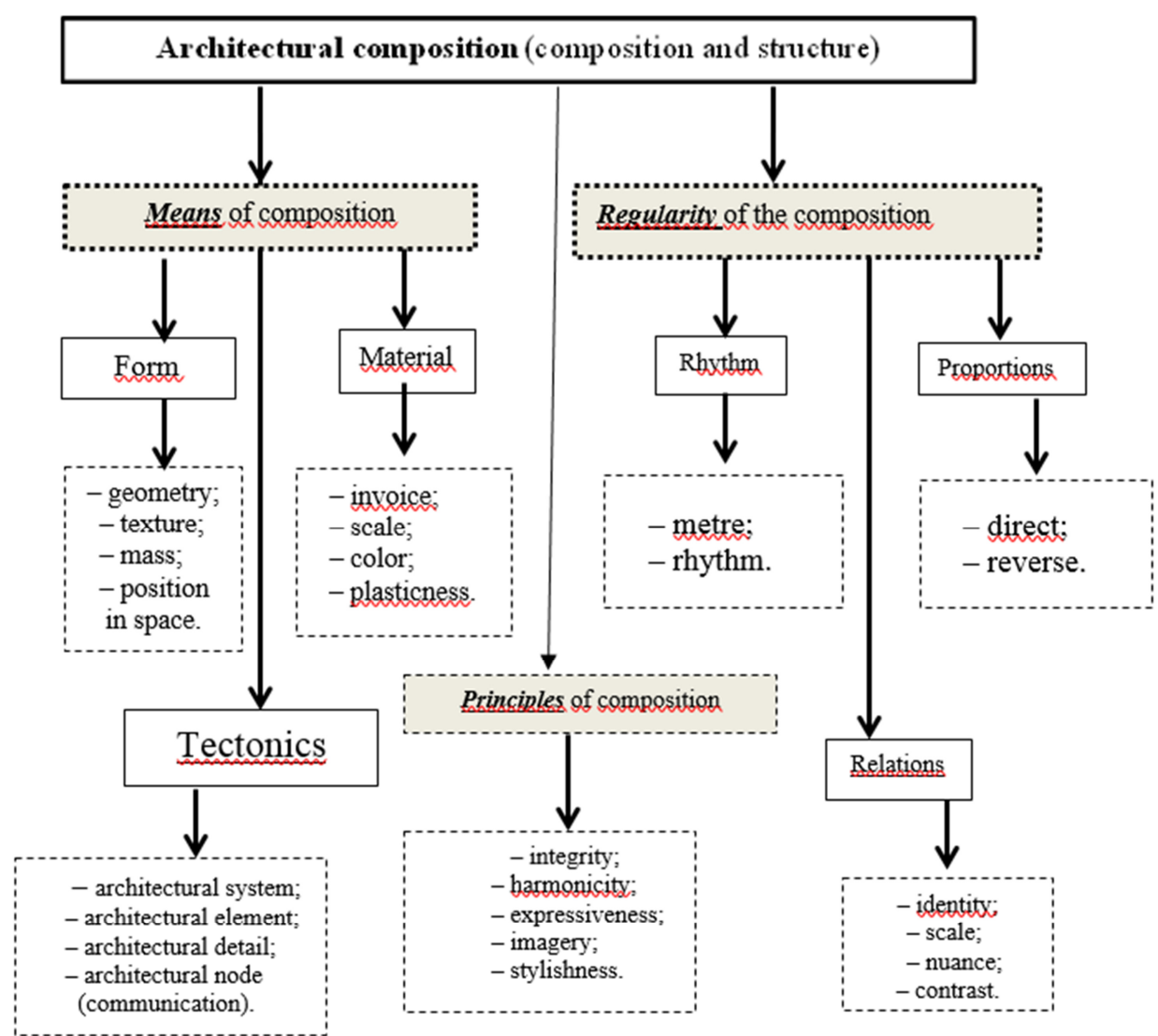

Fig. 1. Structure and composition of categories of architectural composition

The correlation between the form and content revealed in the composition of architectural system, as a characteristic feature of the display method of organization of the system of interaction of main elements and parts (subsystems and elements) and is determined by the unity main components: functions and designs due to artistic content and aesthetic presentation of the architectural design $[6 ; 10 ; 11 ; 12]$.

Traditional compositional solutions of architectural images, in which the synthesis of tectonic features and artistic expressiveness of architectural systems is applied, are diverse in the forms of implementation and emotional impact. 
Each type of system architecture is characterized by certain tectonic features, technical (technological) logic, capabilities and patterns for architectural shaping.

Known from the time of practical activity of the ancient Roman architect Vitruvius formula (rule, triad):" benefit - strength - beauty", over time has been transformed into a traditional Canon that determines approaches to solving architectural problems $[13,14]$.

The traditional format of architectural composition (in its various forms) also implies adherence to the fundamental (traditional) Canon of architecture, despite the fact that the "Vitruvius formula" assumes the interaction of quite contradictory components (formally considered, from the conditions of their equilibrium significance, despite some established sequence of their implementation).

\subsection{Characteristics of the complex properties of manufacturability}

The traditional view of the features of the architectural systems (architectural images) through the organization of ways of interaction of functional, constructive, aesthetic and architectural composition practically does not affect the technical (technological), organizational, managerial, economic and other relations, directly interacting and contributing to the achievement of the final result - set of image and object space, designed for certain functions.

The relationship between the conditions of the organization of the unity of the compositional solution of the architectural image and the ways of their practical implementation through appropriate techniques (operations) can be characterized by a complex property of manufacturability $[15 ; 16 ; 17 ; 18 ; 19]$.

Under the manufacturability of the architectural image (or technological conditions for the formation of an integral composition of the architectural image) is meant to display the parameters of space-planning (composite) solutions, design and artistic solutions through rational technological methods (for all stages of construction production), taking into account the characteristics of the state and availability of material and intangible resources (see figure 2).

The complex characteristic (property) of manufacturability is associated with the peculiarities of the formation of architectural systems at the appropriate stages: manufacturing, transportation to the installation site in the design (functional) position, construction (installation) and operation [20]:

- manufacturability - the degree of approximation properties and indexes architectural systems (structures) to a condition corresponding to minimum costs: cost and complexity of manufacture; the quantity, weight and volume of items; the number and complexity of changes (impacts) the conditions of manufacture;

- manufacturability of transportation is the degree of approximation of the properties and indicators of the architectural system (design) to the state corresponding to the capabilities of vehicles designed to move the manufactured structure to the place of construction;

the mounting workability is the degree of approximation properties and indexes architectural systems (structures) to a condition corresponding to minimum costs: cost and manufacturability operational-is the degree of approximation of the properties and indicators of the architectural system (design) to the state corresponding to the minimum number of costs: the cost and complexity of maintaining (restoring) the established technical condition; to ensure durability (life cycle); to display the established artistic and aesthetic level of the internal space; to harmonize relations with the surrounding external space. 


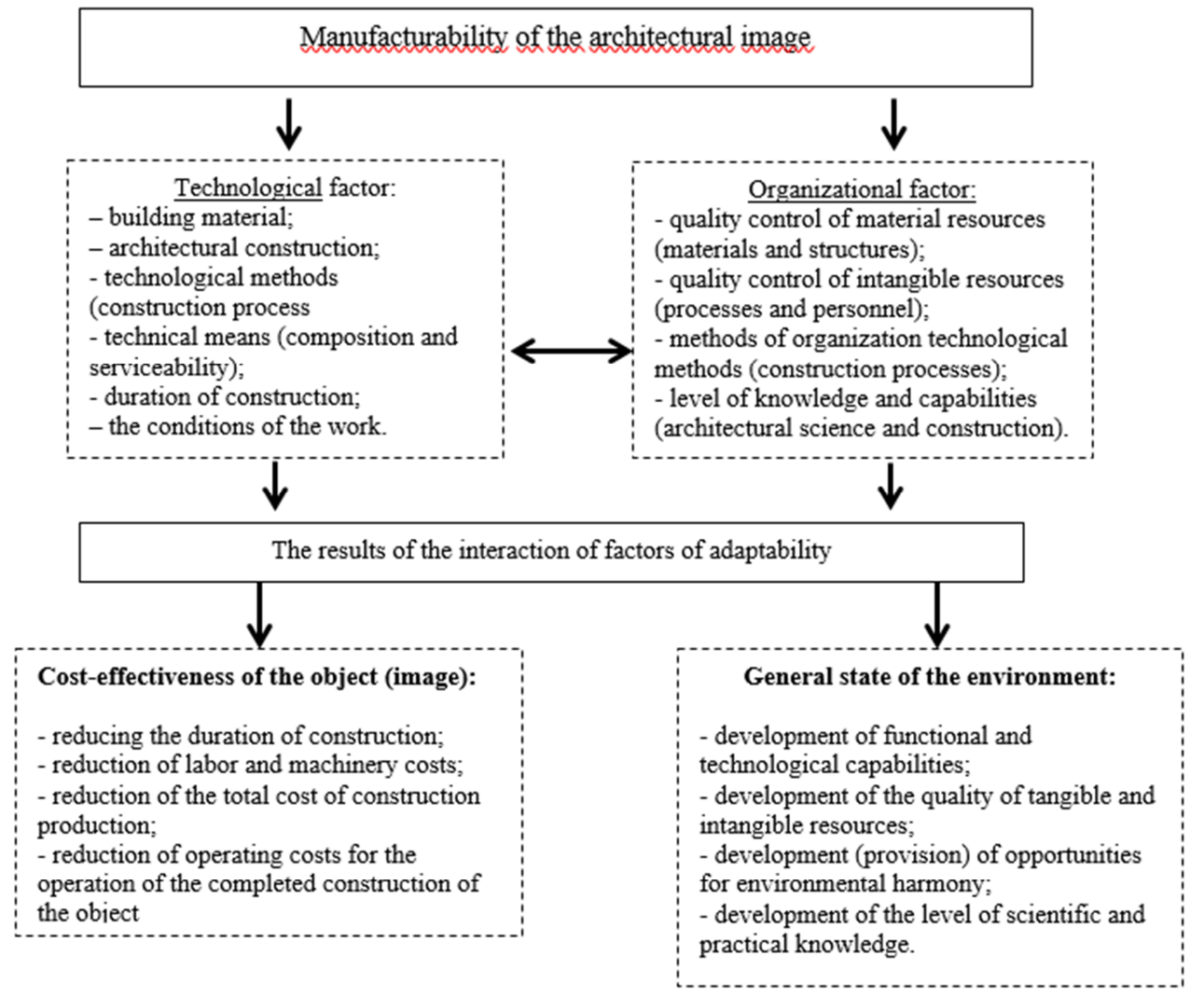

Fig.2. Interaction of factors and results of manufacturability

Each of the types of technology must be viewed in relationship relative to adjacent legs, as composite solutions architectural systems, tech at one stage may be less technologically advanced or not technologically advanced at the subsequent stages of the life cycle of the architectural object.

The solution of problems aimed at the implementation of technological properties in the algorithm of compositional solution formation (ensuring the established or prospective level of technological effectiveness) of architectural systems involves the implementation of a complex of organizational, design, technical and economic measures:

- assignment of criteria, quantitative and qualitative characteristics (indicators) of manufacturability;

- research and forecast of technological increase of individual structural elements and architectural systems as a whole;

- determination of the optimal structure of the architectural system according to established and / or prospective criteria of manufacturability;

- ensuring the accepted (or established) indicators of manufacturability for the manufacture, transportation, construction (installation) and operation of structural (structural) elements of each of the possible architectural systems.

Quantitative and qualitative indicators of the complex properties of manufacturability can characterize numerous subjective and objective features of the tectonic display of the state, the behavior of individual structural elements and the functional quality of the architectural system as a whole [10;20]. 
The formation of modern and promising samples of figurative and stylistic directions of architectural creativity is accompanied by the evolution of known parameters and the revolutionary organization of new properties of materials, technological methods of shaping architectural images.

\section{Results}

The analysis of the unity of the main components (structural, functional, artistic and aesthetic) of architectural objects and their imaginative representations. The necessity of development of methodical apparatus of architectural composition for the development of rational and artistic architectural solutions is shown and substantiated.

The way of development of the established order of the organization of tectonic interaction of architectural system and volumetric-spatial composition by means of manufacturability as the structural component promoting the solution of the main tasks of architectural activity is offered: functional organization of space; harmony and esthetics of the form of an architectural image.

\section{Discussion}

The ability and disposition to possible structural, functional and artistic transformations is a promising feature and potential area of application of architectural systems for various functional purposes. The functional quality of perspective architectural objects is determined by the "canonical" components of a single compositional solution, which will be implemented tectonic display of advanced technological methods of shaping (construction) and methods of organization of internal space.

\section{Conclusion}

Currently, insufficient attention is paid to the issues of theory and practice of application of manufacturability (technological methods of traditional and non-traditional types) as a priority component of a single composite solution of architectural systems. The principles of formation of effective, stable and safe architectural systems designed to solve the problems of formation of perspective functional quality of architectural objects should be developed by taking into account the priority of the complex properties of manufacturability.

\section{References}

1. I. A. Dobritsyna, From postmodernism to nonlinear architecture: Architecture in the context of modern philosophy and science (2007)

2. A. Matthew, Cohen, M. Delbeke, Proportional Systems in the History of Architecture (2018)

3. R.Krier, Architectural composition. Rome: Rizzoli (1988)

4. A. A. Pleshivtsev, Compositional techniques in architecture (2017)

5. Francis D. K. Ching, Architecture: Form, Space, and Order (2007)

6. M. W. Maier, E.Rechtin, The Art of Systems Architecting (2009)

7. J. Madge. Type at the origin of architectural form. // The Journal of Architecture, 1, 1-34 (2007)

8. Yonca Hurol. The Tectonics of Structural Systems (2015)

9. M. Leyton, Group Theory and Architecture 2, 4, 8-18 (2001) 
10. C. Schwartz, Introducing Architectural Tectonics: Exploring the Intersection of Design and Construction (2016)

11. M. V. Shubenkov, Structure of architectural space (2006)

12. S. Stewart, Architectural Theory Review, 2,186-200 (2013)

13. M. Fazio, M.Moffett, L. Wodehouse, A World History of Architecture (2008)

14.Vitruvius. Ten Books on Architecture (2009)

15. D. Khodzhaev, B. Normuminov, Y. Mustapakulov, A.Mottaeva , E3S Web of Conferences, 110, 01045, (2019) doi.org/10.1051/e3sconf /201911001045

16. K.-E. Kurrer, P. Thrift, E. Ramm, The History of the Theory of Structures (2018)

17. E. Allen, J. Iano, Fundamentals of Building Construction: Materials and Methods (2013)

18. N. Sandaker, P. Eggen, R. Cruvellier, The Structural Basis of Architecture (2011)

19. H. Shim, G. Choi, Journal of Building Engineering, 5, 108-114(2017)

20 V. M. Lebedev, I. A. Lomtev, Bulletin of Belgorod state technological University named after V. G. Shukhov, 11, 80-83 (2017) 